\title{
Coin Based Universal Mobile Battery Charger
}

\author{
M.S.Varadarajan \\ Veltech Dr.RR and Dr.SR Technical University Chennai, India
}

\begin{abstract}
The coin-based mobile battery charger developed in this paper is providing a unique service to the rural public where grid power is not available for partialffull daytime and a source of revenue for site providers. The coin-based mobile battery charger can be quickly and easily installed outside any business premises. The mobile phone market is a vast industry, and has spread into rural areas as a essential means of communication. While the urban population use more sophisticated mobiles with good power batteries lasting for several days, the rural population buy the pre owned mobile phones that require charging frequently. Many times battery becomes flat in the middle of conversation particularly at inconvenient times when access to a standard charger isn't possible. The coin-based mobile battery chargers are designed to solve this problem. The user has to plug the mobile phone into one of the adapters and insert a coin; the phone will then be given a micro-pulse for charging. It does not bring a mobile from 'dead' to fully charged state. The charging capacity of the mobile is designed with the help of pre defined values. It is, of course, possible to continue charging the mobile by inserting more coins. This compact and lightweight product is designed to cater for the growing number of rural mobile users worldwide. A suitable microcontroller is programmed for all the controlling applications. The source for charging is obtained from direct power grid and solar energy in case of non availability of grid power.
\end{abstract}

Keywords: - Mobile Phone, Battery Charger, Adapters, Charging-pulse, Microcontroller, P.V.solar panel

\section{INTRODUCTION}

The growth of mobile phone market is phenomenal in recent years and the need for charging the mobile battery is required anytime and anywhere. In many developing countries the grid power is not available for few hours to several hours on daily basis especially in semi urban and rural areas where the mobile phones are the essential communication device. While the urban population use more sophisticated mobiles with good power batteries lasting for few days, the rural population buy the pre owned mobile phones that require charging frequently even two or three times a day. In the event of unpredictable grid power and availability of abundant solar power. a coin based universal mobile battery charger is designed and developed in this paper. This device is like a vending machine for mobile battery charging at kiosks and the user has to plug the phone into one of the adapters and insert a coin for charging at a constant current for a definite duration.

The solar power application to battery charging has been studied in the past. Solar chargers convert light energy into DC current for a range of voltage that can be used for charging the battery. They are generally portable but can also be firmly mounted. In this design of coin based mobile charger a fixed solar panel of size $635 \times 550 \times 38 \mathrm{~mm}, 37 \mathrm{WP}$ is used to charge the battery upto maximum $2.0 \mathrm{amp}$ in bright sun light.

In this paper, the design and development of a coin based universal mobile battery charger based on main power and solar power is discussed and this is primarily for rural areas where the mobiles are basic needs for communication and the main power is not available all the time. The motivation for this research came from the published papers[1to 3].

\section{BASIC ASSUMPTIONS}

The design of coin based universal mobile battery charger is based on the following assumptions:

- Maximum solar energy is used for charging the lead acid battery inside the mobile battery charger to keep it charged fully all the time

- The charging current is upto 4.5AH @ 6vDC and this takes care of the mobiles manufactured by Nokia, Sony-erricson, Blackberry, HTC and others of first and second generation mobiles.

- A single solar panel of size $635 \times 550 \times 38 \mathrm{~mm}, 37 \mathrm{WP}$ capable of supplying upto $2.0 \mathrm{amp}$ is used.

- Provision to charge maximum 10 different types of mobiles is provided.

- Insertion of a fixed coin size for charging 
3. MOBILE CHARGER DESIGN

The basic block diagram of the mobile battery charger is given in Fig.1.

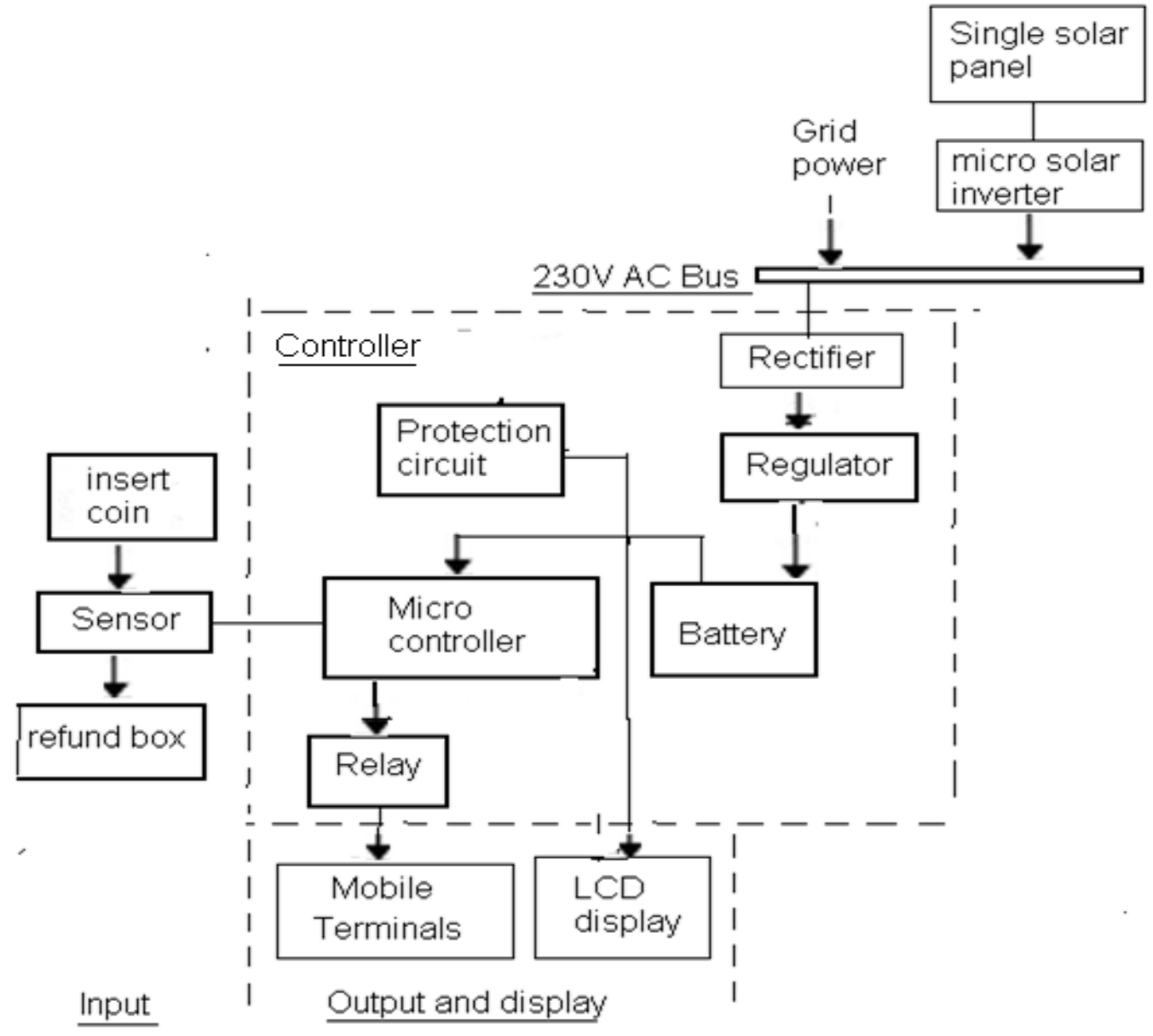

Fig. 1 Basic Block Diagram of a Universal Mobile Battery Charger

\subsection{Input Stage}

The mobile battery charger starts charging a mobile connected to it when a coin is inserted at the coin insertion slot at the input stage. The type of coin and the size will be displayed at the LCD display for the user so as to ensure correct coin insertion. Any other coin, if inserted in the slot will be returned to refund box. A sensor attached to the coin insertion slot accepts the coin into the battery charging unit and start charging the mobile battery for a specific period controlled by the software of the microcontroller. The sensor is an IR sensor. The resistance of the sensor decreases when IR (infrared) light falls on it. A good sensor will have near zero resistance in presence of light and a very large resistance in absence of light. When the coin obstruct the IR light falling on a sensor, it sends a pulse to the control unit authorizing the start of charging the mobile battery connected to the device. Two IR sensors are used for positive authentication of the charging process.

3.2 Controller

This section acts according to the input signal from the sensor circuit. Coin accepted or rejected is based on the diameter of the coin. This invokes microcontroller along with LCD interface displays the selection of mobile option if particular mobile is selected for charging the corresponding routine is activated and charge the mobile for a particular duration of time. When the routine completes, it indicates charge complete message through LCD display. Similarly the same procedure is followed for charging more than four different mobiles simultaneously .The simple routine is indicated through flowchart as shown in the Fig 2.

3.3 Output and Display

The LCD displays all the information to the customer as and when required. When the mobile battery is connected, it displays" Insert Coin". While charging it displays "Charging" and at the end of charging cycle it displays "Charge completed". For charging continuously the coin has to be inserted when the display shows 
"Charge Completed" The output has 10 terminals for connecting different types of mobile batteries and 7 of them are internally connected for charging mobile batteries of different make as shown in Table 1 below:

Table 1: Charging Requirements of Mobile Batteries

\begin{tabular}{|l|l|l|l|}
\hline SI.NO & Mobile Type & $\begin{array}{l}\text { Maximum Charging } \\
\text { Voltage }(\mathrm{V})\end{array}$ & $\begin{array}{l}\text { Maximum Charging } \\
\text { Current }(\mathrm{mAh})\end{array}$ \\
\hline 1 & Samsung & 5.7 & 3400 \\
\hline 2 & Sony Ecrisson & 4.8 & 900 \\
\hline 3 & Nokia & 4.8 & 1500 \\
\hline 4 & LG & 5.5 & 2100 \\
\hline 5 & Panasonic & 3.7 & 1200 \\
\hline 6 & HTC & 5.5 & 1800 \\
\hline 7 & Black berry & 3.7 & 1300 \\
\hline
\end{tabular}



Fig.2 Flow Chart for the Coin Based Universal Mobile Battery Charger

\subsection{Power}

The salient feature of the universal mobile battery charger is that it draws power from the solar energy during the day time for charging the internal battery of the controller. Only if additional power is required, then the grid power is used. A solar micro inverter has been designed for supplying $230 \mathrm{v}, 50 \mathrm{~Hz}$ so that both grid power and the solar power are connected in parallel with a switch to changeover from one to the other. 


\section{MICRO SOLAR INVERTER}

The solar panel required for the application is given in Fig. 3. And the micro solar inverter designed and developed is shown in Fig. 4.

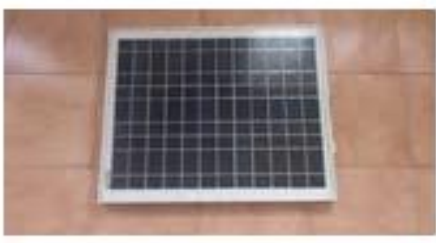

Fig. 3 Solar Panel

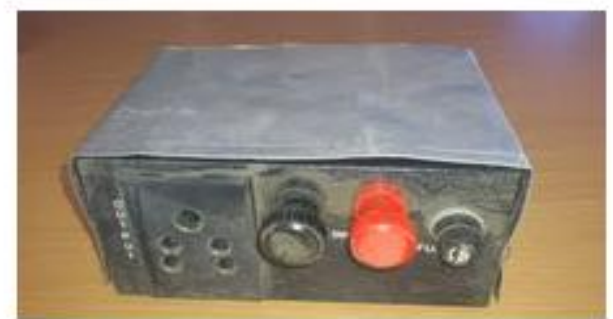

Fig. 4 Micro solar Inverter

The architecture of a micro solar inverter is given in Fig.5. It consists of an astable multi-vibrator tuned for $50 \mathrm{~Hz}$. This is then converted to a pure sine wave using a converter. This is further power amplified and connected to a step up transformer load. The secondary of the transformer gives $230 \mathrm{~V} \mathrm{AC,} 50 \mathrm{~Hz}$.

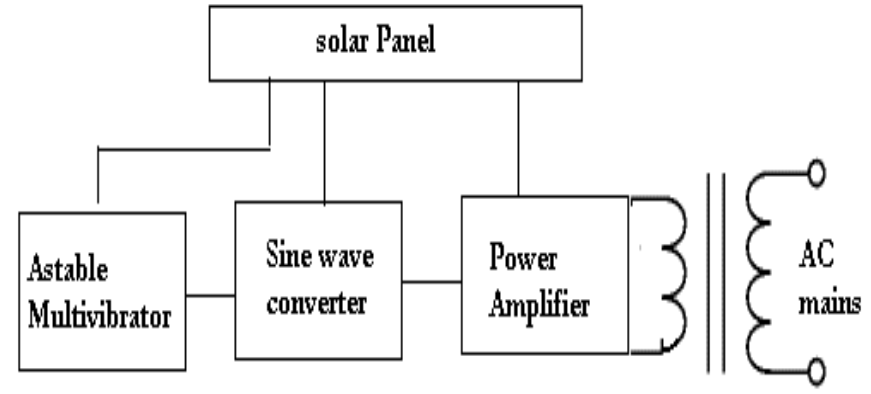

Fig. 5 Architecture of a Micro Solar Inverter

The laboratory model is designed for a 36 cell solar panel of size $635 \times 550 \times 38 \mathrm{~mm}$ with power output $37 \mathrm{wp}, 17.1 \mathrm{~V}_{\mathrm{mpp}}$. The I-V characteristics of the solar panel is shown in Fig.6. The characteristics are taken for dark, moderate solar irradiance and high intensity solar irradiance.



Fig. 6 I-V characteristics of a solar panel

The micro solar inverter is mounted behind the solar panel, compact in size and the DC voltage from the solar panel is used as bias for the electronic circuit as shown Fig.5. The interconnection of solar power to the mobile battery charger is shown in Fig. 7 . 


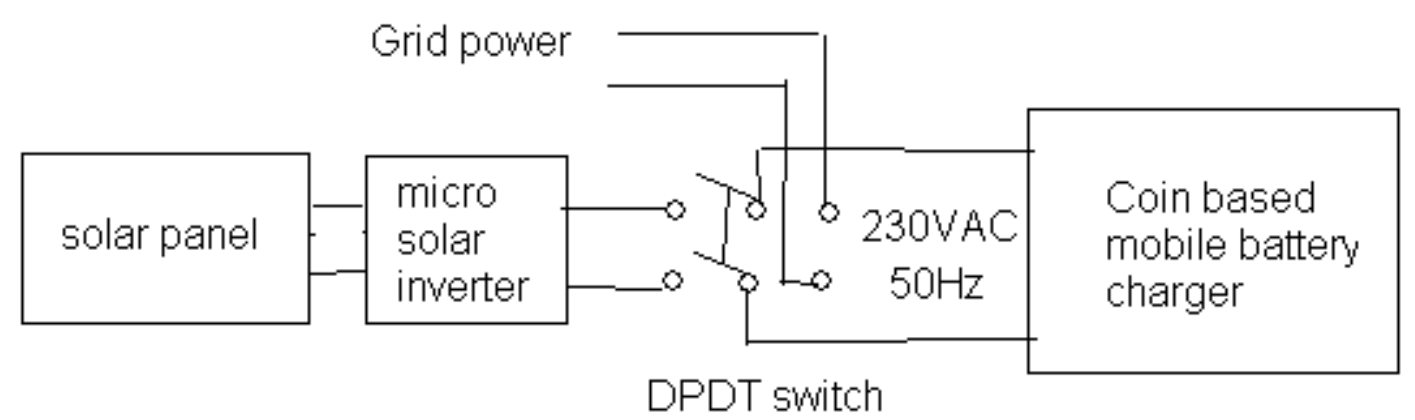

Fig.7 Interconnection of power supply to Mobile Battery Charger.

\section{CONCLUSION}

In this paper, a novel method of charging mobile batteries of different manufacturers using solar power has been designed and developed for rural and remote areas where the grid power is not available all the time. The mobile communication has become a necessity even in rural areas and this device is useful for charging mobile batteries as these mobile battery chargers can be installed in kiosks at various places for the convenience of mobile users. The final prototype made and tested is shown in Fig. 8 and the complete specifications are given in Table 2.


Fig. 8 the Final Prototype of Coin Based Universal Mobile Battery Charger and The typical Charging pattern. 
Table 2. Specifications of a Mobile Battery Charger

\begin{tabular}{|l|l|l|}
\hline S.No & Parameter & Description \\
\hline 1 & $\begin{array}{l}\text { Input } \\
\text { a. Coin } \\
\text { b.Voltage }\end{array}$ & $\begin{array}{l}\text { If the size of the coin doesn't match ,the coin will be rejected } \\
110-240 \mathrm{vAC}, 50-60 \mathrm{~Hz}\end{array}$ \\
\hline 2 & $\begin{array}{l}\text { Max.Output } \\
\text { Voltage }\end{array}$ & $6 \mathrm{~V}$ \\
\hline 3 & Max.Output current & $4.5 \mathrm{Ah}$ \\
\hline 4 & Dimension & Small Size \\
\hline 5 & $\begin{array}{l}\text { Ambient } \\
\text { Temperature }\end{array}$ & $(0-50)^{\circ} \mathrm{c}$ \\
\hline 6 & Coin Insertion & Rs2 coin of Indian currency \\
\hline 7 & $\begin{array}{l}\text { Operating } \\
\text { Environment }\end{array}$ & Indoor/Outdoor \\
\hline 8 & Net weight & 700 to 900 gms. \\
\hline 9 & Humidity & $<80 \%$ \\
\hline
\end{tabular}

\section{References}

1. Pulvirenti, F. Milazzo, P. Ursino, R, Charger power switch for mobile phones, Analog and Mixed IC Design, 1997. Proceedings. 1997 2nd IEEE-CAS Region 8 Workshop_,12-13 Sep 1997, Pg 97 - 100.

2. Pastre, M. Krummenacher, F. Robortella, R. Simon-Vermot, R. Kayal, M. Ecole Polytech. Fed. de Lausanne, Lausanne, A fully integrated solar battery charger Circuits and Systems and TAISA Conference, 2009. NEWCAS-TAISA '09. Joint IEEE North-East Workshop

3. , Barth, H. Schaeper, C. Schmidla, T. Nordmann, H. Kiel, M. van der Broeck, H. Yurdagel, Y. Wieczorek, C. Hecht, F. Sauer, D. U., Development of a universal adaptive battery charger as an educational project ,Power Electronics Specialists Conference, 2008. PESC 2008. IEEE, 15-19 June 2008, Pg 1839 - 1845.

4. Bedford, B. D.; Hoft, R. G. et al. (1964). Principles of Inverter Circuits. New York: John Wiley \& Sons, 1964

5. Weidong Xiao, William G. Dunford, Patrick r. Palmer and Antoine Capel, "Regulation of Photovoltaic voltage," IEEE Trans. Industrial Electronics, vol. 54 no.3, pp. 1365-1373, June 2007 